\title{
A MÃE ENSINA, O FILHO APRENDE AS LIÇÕES DO ABC PELO JORNAL ${ }^{1}$
}

\author{
Francisco Ari de Andrade ${ }^{2}$ \\ Ana Maria Leite Lobato ${ }^{3}$
}

\begin{abstract}
RESUMO
A origem desse texto está numa pesquisa desenvolvida junto ao setor de hemeroteca da Biblioteca Pública Governador Menezes Pimentel, onde foi possível a localização dos volumes do Jornal do Ceará microfilmados, tendo em vista ser na Coluna Escola que circularam as aulas de $\mathrm{ABC}$ para a infância pobre. A partir de tal levantamento, é possível refletir uma experiência pedagógica de alfabetização de crianças à distância, contando com a ajuda das "mães de família". Nesse apanágio, eis uma reflexão sobre uma iniciativa educacional desenvolvida no início do século XX, na cidade de Fortaleza, tendo como foco o ensino de lições do abecedário às crianças pobres, excluídas da escola, por meio do jornal impresso. É um estudo no domínio da história da educação teoricamente ancorado em autores que se debruçam sobre a temática e tem norteado a produção historiográfica em educação no Brasil. Publicadas naquela coluna, aquelas lições representavam um paradoxo frente às disparidades sociais da cidade, no começo do século $\mathrm{XX}$, cujos indicadores davam conta de um acentuado número de crianças e de adultos analfabetos. Publicadas em forma de tabelas, as lições do $\mathrm{ABC}$ e seus exercícios de silabação, no preâmbulo de cada aula, eram iniciadas por um lembrete às mães para que as lições, endereçadas à alfabetização das crianças, em domicílio, fossem acompanhadas, exclusivamente, por elas. Palavras-chave: Lição; Criança; Alfabetização; Abecedário.
\end{abstract}

\section{MOTHER TEACHES, THE SON LEARNS THE ABC LESSONS IN THE NEWSPAPER}

\begin{abstract}
The origin of this text is a research developed in the sector of hemeroteca Governor Menezes Pimentel Public Library, where it was possible the location of the microfilmed volumes of the Jornal do Ceará in order to be circulated in the Column Escola where classes $\mathrm{ABC}$ to poor crildren. From this survey it is possible to reflect an educational experience of children's literacy in the distance, with the help of the their "mothers". In this prerogative, that is a reflection on an educational initiative developed in the early twentieth century, in the city of Fortaleza, focusing on teaching the alphabet lessons to poor children excluded from school, through the printed newspaper. It is a study in the field of history of education theoretically anchored on authors who focus on the theme and has guided historical production of education in Brazil. Published in that column those lessons represented a paradox facing the social disparities of the city in the early twentieth century, whose indicators revealed a marked number of children and illiterate adults. Published in the form of tables, those lessons and their exercises of syllabication in the preamble of each class were initiated by a reminder to mothers that the lessons addressed the literacy of children in the household were to be supervised exclusively by them.
\end{abstract}

Keywords: Lesson; Child; Literacy; Alphabet. 


\section{Introdução}

"O ENSINO INTUITIVO: O - ABC EM SEIS LIÇÕES PARA INFÂNCIA POBRE". Eis o título de uma série de lições, que a normalista Ana Facó (1855-1926) ${ }^{4}$ apresentava à sociedade cearense pelo jornal como proposta pedagógica, no começo do século XX, na cidade de Fortaleza, movida por benemerência individual, de ensinar às crianças o abecedário. Para concretizar tal experiência, clamava a ajuda das "mães de família" para dar cabo de acompanhamento do processo de alfabetização dos filhos.

Publicadas na Coluna Escola, do Jornal do Ceará, editado periodicamente na capital do Estado, aquelas lições representavam um paradoxo frente às disparidades sociais da cidade, no começo do século XX, cujos indicadores davam conta de um acentuado número de crianças e de adultos analfabetos. Ao solicitar no projeto o envolvimento das mães no sentido de ajudar na alfabetização dos filhos, sob a orientação e a supervisão pedagógica a distância da referida mestra, e autora das lições, partira do pressuposto da escolaridade dessas mães. Apesar de imbuída de boa vontade, em proporcionar a educação para as massas, a proposta da educadora Ana Facó não atenderia a maioria da população urbana, concentrada desordenadamente nos subúrbios da cidade, muito menos da massa sertaneja, desassistidas do poder governamental. O impedimento da expansão daquela ação pedagógica começaria pelo acesso ao jornal, a depender de recursos financeiros, como também, pelo fato de que a maioria das mães iletradas em nada podia colaborar com a educação formal dos filhos.

No entanto, a relevância de trazer para o debate o relato daquela experiência educacional é, pelo valor que representa, como algo progressista para aquele momento histórico, ou seja, uma iniciativa muito à frente de seu tempo. Sinalizava uma época em que mulheres educadoras vinham se preocupando com a educação das massas, a criarem estratégias inovadoras de educação popular, por meio da utilização de mídias da ocasião como instrumento possível para a alfabetização de crianças, a distância. Não obstante, o presente artigo põe em relevo uma iniciativa pedagógica, desenvolvida no início do século $\mathrm{XX}$, na cidade de Fortaleza, de ensinar lições do abecedário às crianças pobres, excluídas da escola, por meio do jornal impresso.

$\mathrm{O}$ artigo aponta as bases e ações que emoldurava aquela experiência pedagógica, precursora de uma forma de educação a distância inspirada numa ação lúdica para a alfabetização de crianças, que envolvia a atuação da referida normalista e das mães e, principalmente, o jornal.

\section{Fundamentação das aulas do ABC}

Fundamentadas na Gramática Complementar da Língua Portuguesa, de autoria do educador manauara Paulino de Brito ${ }^{5}$, foram previstas a publicação de seis lições na Coluna Escola, do Jornal do Ceará, nas edições dos meses de março e abril de 1904.

No entanto, um levantamento junto ao setor hemeroteca, seção de microfilmagem, da Biblioteca Pública Menezes Pimentel, do Estado do Ceará, foram localizadas, apenas quatro das seis lições previstas. Os números seguintes do referido jornal não trazem mais as duas lições restantes. Nesse sentido, há de se interrogar o motivo de tal aborto, já que havia entusiasmo da normalista Ana Facó em alcançar o objetivo de publicação das seis lições. 
Entretanto, dentre o que foi localizado como fonte histórica é possível tecer uma demonstração do componente didático, cuja reflexão sobre tal ação pedagógica permite uma atenção especial à forma como as aulas do $\mathrm{ABC}$ foram montadas para atingir os objetivos pedagógicos previstos.

Publicadas em forma de tabelas, no preâmbulo das lições do ABC e seus exercícios de silabação, seguia um lembrete chamando a atenção de serem aquelas aulas propostas à alfabetização das crianças sem escolas em seu próprio domicílio mediadas pela força de vontade das "mães de família".

Pelo fato de ter sido eleito o jornal como o instrumento educacional, capaz de possibilitar a alfabetização das crianças pertencentes às camadas populares, mesmo que tal proposta estivesse dosada de altruísmo e benemerência, aquele empreendimento indicava uma intenção de educação a distância, embora tal fenômeno tenha se tornado fato educacional brasileiro na segunda metade do século XX.

$\mathrm{O}$ público-alvo a quem se destinavam as aulas do $\mathrm{ABC}$ compreendia crianças de cinco a oito anos de idade. A recomendação postada no alto da coluna, de onde seguiam as ditas lições, era que o alfabeto fosse ensinado "brincando", tendo em vista que, as lições haviam sido pensadas de maneira tal que não exigisse tamanho "esforço mental" a ponto de provocar "cansaço" nas crianças.

Assim ficou acertado pela referida professora que, ao final de um mês de aulas, seriam aplicadas sabatinas aos alunos. Dentre aqueles que apresentassem a coleção das aulas no jornal "limpa e sem rasgões" recebiam brinquedos como incentivo.

Ainda que as fontes localizadas não permitam uma análise detalhada da ação e do alcance pedagógico daquela experiência escolar cearense, junto à população excluída da "Fortaleza Descalça", 6 admite-se ser instigante uma apreciação da temática inserida nas páginas de um jornal de orientação ideológica republicana.

Principalmente numa época caracterizada pela ineficácia da escola pública, devido à prevaricação do Estado brasileiro naquilo que rezava a Constituição de 1891, pelos percentuais insatisfatórios de investimento público para o setor e pelos altos índices de analfabetismo da população em idade escolar, deve-se admitir a notoriedade daquela iniciativa pedagógica, mesmo ignorando que a quase totalidade das mães se encontrasse em estágio escolar insuficiente para acompanhamento das lições dos filhos.

\section{O Método de educar as crianças pobres pelo jornal}

A proposta pedagógica de facilitar às crianças pobres a aquisição de leitura e escrita, por meio das lições do ABC impressas na Coluna Escola do Jornal do Ceará, tem o mérito de propor educação a um público ampliado, mesmo que naquela época não houvesse clareza sobre a importância da utilização da tecnologia disponível, para tal fim, que fazia circular conhecimento, informações e ideias pelos jornais e pelos almanaques, pondo em movimento a imprensa cotidiana das cidades brasileiras.

A idealizadora do projeto demonstrava possuir uma convicção moderna de educação, fazendo prevalecer a ideia de que a imprensa podia desempenhar um grande papel social, por facilitar a chegada da escola às classes populares, que estivessem excluídas das escassas unidades de ensino espalhadas pelo estado.

Não obstante, aquela iniciativa educacional era nutrida por uma crença de Fortaleza cidade moderna, no começo do século $\mathrm{XX}$, porque se enquadrava como capital a se 
beneficiar das tecnologias do tempo, segundo as inferências do sociólogo Gabriel Tarde (1992), que apontava como pilastras do mundo moderno o telégrafo, a estrada de ferro e, principalmente, a tipografia responsável pela imprensa cotidiana.

Além da Coluna Escola, encontrava-se, também, outra intitulada Para as creanças - Minha Palmatória. Em tal coluna, em cada edição do Jornal do Ceará seguia um conto infantil, direcionada aos pais para lerem com seus filhos. Ao final de cada historinha havia uma orientação moral, para que as crianças meditassem e se orientassem para a vida em sociedade.

\section{O método das Lições de Coisas para a escola primária}

Esse método é originário das principais nações europeias decorrente do debate nas conferências educacionais e nas exposições de materiais pedagógicos, da segunda metade do século XIX, tendo em vista a necessidade de expansão da educação primária às massas populares. (SAVIANI, 2008).

O Método Intuitivo, ou das Lições de Coisas, para a instrução primária foi instituído na escola pública brasileira por meio do Decreto $\mathrm{N}^{\circ}$ 7. 247, de 19 de abril de $1879,{ }^{7}$ que visava, dentre outras prioridades, à organização pedagógica do sistema escolar na Corte, configurando-se como modelo a orientar a organização dos sistemas nas províncias do império. Tal decreto passaria para os anais da história da educação como Reforma Leôncio de Carvalho. À luz do debate educacional, em setembro de 1882, o causídico Rui Barbosa, à frente da Comissão de Instrução Pública, submeteu um parecer à Câmara dos Deputados, que nunca fora votado, reforçando a importância do método intuitivo para a escola primária brasileira, por aproximar as crianças ao mundo da observação e da experiência. (MOACYR, 1937).

Todavia, o referido decreto ao incluir a recomendação do Método Intuitivo dava vazão às discussões nacionais em defesa da escola pública republicana. Tal discussão associar-se-ia ao advento da introdução da escola primária graduada, isto é, do grupo escolar, na cultura educacional brasileira, refletida a partir da experiência do estado de São Paulo. (MARCÍLIO, 2005).

No Ceará, seguindo o debate educacional que emanava do sul do país, oficializaria a utilização das lições de coisas nas escolas públicas, por via da publicação do Regulamento de Instrução Primária, em 13 de março de 1905.

Conforme o que rezava aquele documento, no seu artigo $2^{\circ}$, era chamada a atenção para a introdução do ensino graduado. Outra conquista trazida pelo referido, no seu Capítulo III, artigo 13, inciso V, definia o plano de estudo para o ensino primário, assegurando ser o método de lições de coisas necessário, porque aproximava as crianças ao campo das ciências da natureza.

\section{A cultura dos Grupos Escolares e o método das Lições de Coisas}

A instituição de grupos escolares demarcaria a introdução da escola e da pedagogia moderna no Brasil no final do século XIX, como tentativa de superação do modelo das escolas de ensino mútuo. A partir de então, as escolas graduadas foram se disseminando pelos demais estados da federação, figuraram no sistema educacional brasileiro até o início 
da década de 1970, quando a Lei 5692/71 universalizou o ensino primário e o ginasial em nível de primeiro grau, abolindo aquele modelo de escola elementar. (VIDAL, 2013).

Os grupos escolares foram modelos de escolas urbanas, mesmo que sua existência no meio rural tenha se conservado nas sedes dos municípios brasileiros. No âmbito escolar, encerravam um tipo racional de organização didático-pedagógica e administrativa da educação. (VEIGA, 2007). De proposta curricular de orientação laica e científica, a instituição do método intuitivo buscou estabelecer um novo ritmo à escola primária. Consoante àquele modelo, os alunos eram agrupados em sala de aula por relação de pertinência, conservando a relação da idade com a série. Vale ressaltar que a presença da diretora na escola encurtava a distância entre a instância fiscalizadora e o (a) professor (a). (SOUZA, 2008).

De acordo com a orientação pedagógica das Lições de Coisas, o processo de ensino e aprendizagem de saberes era consubstanciado em três dimensões: a educação dos sentidos, a educação das coisas e a educação pela experiência. Pelo visto, aquela orientação educacional rompia com um modelo pedagógico pautado na memorização de conteúdos e na emulação entre os alunos, de característica tradicional. (VALDEMARIN, 2004).

Valdemarin (2004) considera não ser simples precisar a origem do método intuitivo, embora tal assunto estivesse presente no debate da filosofia educacional dos iluministas. Contudo, a sua evidência foi reconhecida a partir da segunda metade do século XIX, quando as ideias pedagógicas de Pestalozzi e Froebel fundamentaram experimentos educacionais com crianças pobres na Europa, renovando as práticas de ensino e inovando o processo de aprendizagem da leitura e da escrita.

\section{O prenúncio do Grupo Escolar, no limiar do século XX, em Fortaleza}

Na ocasião da leitura da mensagem enviada à Assembleia Estadual para o ano de 1905, o presidente Nogueira Accioly se debruçara sobre uma análise da realidade do ensino primário no Ceará ao mesmo tempo que estimulara o debate acerca da necessidade de modernização da escola primária, com a introdução do grupo escolar. (ANDRADE, 2008).

Inicialmente, a fala do presidente traçava um paralelo entre a ignorância e a criminalidade, reportando-se ao poeta Victor Hugo que havia destacado em certa ocasião para o governo "abrir escolas era fechar prisões" no futuro. Dessa maneira, da defesa da educação dependia o futuro da sociedade, pois por meio dela seriam desenvolvidos os "mais sérios interesses humanos". A oferta da instrução primária estaria lançando a "sorte da família" brasileira, coadunando com "a prática e o desenvolvimento das instituições políticas", fortalecendo a nação e a cidadania.

$\mathrm{Na}$ continuidade de sua exposição, destacaria ainda o presidente Accioly ser a "instrução primária" um fator de "progresso e não mero adorno pessoal", sendo importante ao governante não "o cruzamento dos braços" em face de demandas sociais, mas, de enfrentamento da questão, a exemplo dos governos de países dos "grandes centros industriais", onde a escola aproximava "os alunos do mundo prático", a criar, assim, uma relação estreita entre "o mundo do estudo e o mundo das fábricas". No entanto, se o discurso do governo demonstrava entusiasmo pelo progresso da escola primária, na prática a realidade escolar contradizia tal discurso. 
Conforme Vieira (1905), no início do século XX o sistema cearense de ensino contabilizava um total de 246 escolas assim distribuídas: 21 na capital, 75 nas cidades, 82 nas vilas e 70 nas povoações. Naquela época, a população total do estado era estimada em torno de 849.118 habitantes, sendo que, de tal total, 48.369 eram habitantes da cidade de Fortaleza.

Ao considerar a notória escassez de recursos públicos destinados às escolas associada à ausência de ações públicas, local e nacional, para enfrentamento das secas periódicas no sertão dos estados do Norte, que muito comprometia o erário, a inoperância das diretorias de instrução pública na fiscalização, acompanhamento e avaliação das unidades de ensino, bem como o distanciamento entre as escolas da capital, das sedes de cidades, das vilas e das povoações interioranas é de se conjecturar os altos índices de evasão escolar.

No sentido de elucidar tais questionamentos, torna-se relevante a apreciação de alguns dados educacionais extraídos das páginas do Almanaque do Estado do Ceará ${ }^{8}$. Segundo consta, em 1904, período em que começaram as lições do ABC pelo jornal, as 294 escolas primárias cearenses estavam assim distribuídas e organizadas: da capital e sede de cidades 99 unidades de ensino; das vilas 84, das povoações e de arraial somando 111 escolas. O número de matrículas, no entanto, naquele ano chegou a atingir 10.602 alunos, distribuídos entre as 74 escolas do sexo masculino, as 78 do sexo feminino e as 142 de ensino misto. Do total de escolas listadas, a cidade de Fortaleza comportava o número de 24, assim distribuídas: oito do sexo masculino, 12 do sexo feminino e quatro de ensino misto.

Uma reflexão sobre a questão da distorção da matrícula, o referido período anunciava que no decorrido ano de 1905, as 24 escolas primárias de Fortaleza haviam contabilizado um total de 2.015 matrículas. De tal contingente escolar, 763 matrículas eram do sexo masculino, contra 1.252 do sexo feminino. Um dado positivo a ser apreciado em outra ocasião, pelo fato do predomínio de matrículas de meninas. No entanto, quanto à frequência, de um total de 1.614 alunos, havia um déficit de 401 alunos, que, por alguma razão, acabaram se evadindo do espaço escolar.

Fazendo um paralelo entre o índice populacional do estado, em 1904, acima destacado, com a população escolarizável, considerando que desse público, uma grande cifra de pessoas era composta por crianças e jovens em idade escolar, e, mais ainda, que o número de escolas primárias era incompatível à demanda por matrículas, sem esquecer (de destacar) as distâncias que separavam a capital, sede do governo no litoral, das do sertão, espaço social demarcado e controlado por potentados, cuja distribuição de parcos recursos não alcançava a coletividade, assim cabe inferir que uma grande parcela da população em idade escolar estava fora da escola. Talvez movida por um espírito altruísta, mas sem desconsiderar a influência de um pensamento pedagógico da época, possivelmente a gramática do professor Paulino de Brito, anteriormente relatada, a mover o entusiasmo da normalista Ana Facó, ávida por saberes, tenha trazido à baila uma experiência pedagógica de ensinar a infância pobre a ler e a escrever, por meio do acesso ao jornal.

\section{O Método Intuitivo nas lições do ABC pelo jornal}

O Método Intuitivo exigia do aluno a observação e a experiência por meio do contato direto com o objeto de estudo. Nesse sentido, parece que as lições do ABC 
impressas no Jornal do Ceará tenderiam a ser material concreto capaz de facilitar o processo de aquisição do abecedário, pelas crianças.

As aulas de $\mathrm{ABC}$ anunciadas na Coluna Escola, do Jornal do Ceará, vinham sempre acompanhadas de um conto, escrito pela referida professora, que servissem de estímulo à leitura dos pais e que, a partir dali, facilitasse, também, a orientação moral dos filhos. Não há espaço nesse artigo para uma apreciação crítica do conteúdo de tais contos.

Uma apreciação das tabelas contendo as lições que foram distribuídas pelo jornal, permite entender a maneira como as letras foram distribuídas no espaço da folha impressa e a sequência das mesmas na condução do processo de aquisição da leitura e da escrita.

\section{- Primeira lição}

Cada lição era acompanhada da seguinte recomendação didática:

Brincando com seus filhos os Snrs. paes de familia ensinarão o alphabeto ás creanças de 5 a 8 annos, exercitando-as no quadro ac]ima, começando a ensinar por letra, grupo de letra, syllaba, e das palavras simples para as compostas. O jornal publicará lições que não exijam esforço mental nem produzam cansaço. Depois de um mez fará sabbatina, distribuindo brinquedos a seus alnmnos que tiverem guardado a colleção do jornal, limpa e sem rasgões. (Jornal do Ceará. Coluna Escola, p.3. Fortaleza $16 / 03 / 1904)$.

\begin{tabular}{|l|l|l|l|}
\hline A a & $\mathrm{B} \mathrm{b}$ & $\mathrm{C} \mathrm{c}$ & D d \\
\hline BA & $\mathrm{Ca}$ & Da & \\
\hline A & B & A & \\
\hline C & A & D & A \\
\hline Aba & Ca & BA & \\
\hline
\end{tabular}

Como se verifica no recorte acima em destaque, o curso de alfabetização deveria ter uma duração de um mês, pois depois desse período os alunos seriam sabatinados.

Uma apreciação das lições distribuídas na tabela permite compreender a dinâmica das aulas impressas. Cada tabela era composta por quatro colunas com cinco linhas. $\mathrm{Na}$ primeira linha, encontravam-se as quatro primeiras letras do alfabeto escritas em maiúsculas e minúsculas. Na segunda linha, mostra-se uma sequência da junção da primeira consoante, depois da segunda e depois da terceira com a letra a. Inicia-se o processo de soletração da junção de consoante mais vogal. Dava a entender ao aluno que a maioria das palavras se iniciava por consoantes e que a vogal a era sempre a base para a construção de outras palavras. Na terceira linha da tabela, percebe-se que são ocupadas apenas três colunas, prevalecendo a letra $\mathbf{B}$ entre a letra $\mathbf{A}$. A intenção da tabela parecia demonstrar as variações das letras entre maiúsculas e minúsculas, dependo da posição que ocupassem na composição das palavras. Na quarta linha, as quatro colunas são ocupadas com quatro grafemas fora de sequência: C, A, D e A. Supostamente, previa testar o grau de aprendizagem do aluno, evitando que o mesmo decorasse o lugar que cada letra ocupava na escala alfabética. Na última linha, depois de conhecer e identificar a grafia e o som de cada fonema seguia-se o novo processo de soletração de palavras pela junção de consoante entre duas vogais, como exemplo $\mathrm{a}+\mathrm{b}+\mathrm{a}$, formando a palavra aba e de $\mathrm{c}+\mathrm{a}$, formando o som $\mathbf{K}$, finalizando a junção do $\mathrm{b}+\mathrm{a}$, formando o vocábulo $\mathbf{B A}$. 
Encerradas as primeiras aulas do $\mathrm{ABCD}$, o aluno apto ao domínio dos primeiros fonemas, podendo prosseguir para a tabela da aula seguinte com novas letras e novos desafios de soletração de palavras.

\section{- Segunda lição}

A segunda lição foi publicada na edição do dia 16 de março de 1904. A aula viria iniciada com a mesma recomendação didática expressa no preâmbulo da lição anterior. Prática que seguiria em todas as demais.

\begin{tabular}{|l|l|l|l|}
\hline E & F & G & H \\
\hline $\mathrm{Ga}$ & $\mathrm{Fa}$ & $\mathrm{Da}$ & Há \\
\hline $\mathrm{Fa}$ & da, & Fa & Ca \\
\hline $\mathrm{Ça}$ & Fé & $\mathrm{He}$ & Hi \\
\hline $\mathrm{Fa}$ & $\mathrm{Ca}$ & $\mathrm{Da}$ & \\
\hline
\end{tabular}

Seguindo a proposta da lição anterior, a nova dinâmica do processo de ensino apresentava na primeira linha mais quatro consoantes $\mathbf{E}, \mathbf{F}, \mathbf{G}$ e $\mathbf{H}$ acompanhadas das vogais a, e, i. Nas linhas seguintes, as consoantes saiam da sequência e iam se alinhando às vogais, formando novos fonemas.

Uma particularidade percebida em tal lição era o uso da vogal a acentuada graficamente precedida da consoante $\mathbf{H}$ e a vogal e, também acentuada, precedida da consoante $\mathbf{f}$, formando o vocábulo fé. Estava orientado, também, o uso da letra $\mathbf{C}$, com cedilha, antes da vogal a, formando o vocábulo ça.

Como se percebe, por meio do domínio dessa nova série de grafemas e fonemas, o exercício da silabação estava sendo possível aos alunos por meio da composição de palavras dissílabas, tais como: café, faca, fada, caça e faça.

\section{- Terceira lição}

Na terceira lição constava a recomendação didática, aos pais que se faziam de mestres de ensino das crianças:

O professor na primeira linha ensine o nome e fórma das tres primeiras lettras, na segunda exercite o alumno a ligar o nome aos caracteres, e na terceira a syllabal-os. Como faz - b mais a? - $\mathrm{c}$ mais a? O alumno responderá simplesmente ba ou ca. Explique-se o valor da cedilha. Desça-se por fim á leitura dos vocabulos não solettrando mas syllabando. Explique-se a composição da syllaba sempre que for necessario. (Jornal do Ceará, Coluna Escola, p.3. Fortaleza, 30/03/1904).

\begin{tabular}{|c|c|}
\hline Aba & \\
\hline Baba & Aba \\
\hline Caba & \\
\hline Bacaba & Caba \\
\hline Cabaça & \\
\hline
\end{tabular}


De acordo com a tabela acima, prevaleciam exercícios com palavras dissílabas e trissílabas com o uso da vogal a. Um detalhe observado nessa lição era o fato de todas as palavras terem sido criadas a partir das primeiras letras $\mathbf{A}, \mathbf{B}, \mathbf{C}$, ensinadas na primeira lição. Nessa nova sequência estava sendo explorada a função da letra $\mathbf{C}$, principalmente quando havia necessidade do uso da cedilha.

- Quarta lição

Publicada em 14 de abril do referido ano, a lição observada trazia o enquadramento de novas referências para aprimorar o processo de letramento dos alunos. Eis o recorte:

Methodo- Paulino de Brito

Escola do "Jornal do Ceará"

Quarta lição

a b c d e f e f d b a e c f f d e a e a c b e b d e f a c da fa de fe be ce ad ed ef eb ca ça

\begin{tabular}{|l|l|}
\hline Faca & Faca \\
\hline Face & \\
\hline Café & Café \\
\hline Caçada & \\
\hline Cabeça & Cabeça \\
\hline
\end{tabular}

E, logo em seguida, em destaque a recomendação sobre o procedimento didático de como ministrar a lição:

O professor proceda como na lição anterior. Faça notar ao alumno o valôr do accento agudo sobre o e (é) comparando os dois vocabulos face e café. Insista particularmente sobre a fórma e o nome das novas tres lettras. Faça ler todas na ordem, muitas vezes. (Jornal do Ceará, Fortaleza 16.04.1904, p.3).

Destarte, o recorte demonstrava que não havia muito esforço a fazer, nem por parte de quem ensinava e nem, por quem deveria aprender. Aos alunos caberia, apenas, observar os modelos e repeti-los muitas vezes até a fixação da lição, na base de seu entendimento. De acordo com a orientação pedagógica acima destacada pela educadora Ana Facó, os elementos importantes para a aquisição da leitura e da escrita eram a observação da lição apresentada, a prática do exercício pautado na observação e na repetição das letras e, finalmente, por meio de analogia de palavras, em que fosse identificada, principalmente, a diferença quando fossem acentuadas.

No preâmbulo de tal lição, uma novidade chama a atenção do leitor. Trata-se de uma referência ao método gramatical desenvolvido pelo que, supostamente, foi aquela de que a professora Ana Facó recebia orientação pedagógica para redação das aulas impressas pelo jornal.

Todavia, ao se admitir, no início do século XX, a escassez de produção e circulação de manuais pedagógicos e de gramáticas na orientação do trabalho docente para a escola primária, por se verificar referência ao professor Paulino de Brito. Por isso, não se deve desconsiderar que aquele material didático circulasse pela cidade de Fortaleza e influenciasse, pedagogicamente, a prática das normalistas cearenses em alfabetizar crianças.

A lição de número quatro se iniciava pela leitura "em carreira" de uma linha composta por uma sequência das letras $\mathbf{a}, \mathbf{b}, \mathbf{c}, \mathbf{d}, \mathbf{e}, \mathbf{f}$. Na continuidade, as letras se 
misturavam. Saindo de seus lugares, iam se agrupando em posições contrárias na escala da distribuição inicial. Tudo leva a admitir que, uma vez a letra saindo da ordem, tal exercício forçasse o aluno a conhecer as letras, independente do lugar que ocupassem na escala alfabética, ao invés do uso da "decoreba". Na continuidade, inicia-se a junção das consoantes com as vogais formando as monossílabas da fa de fe be ce ad ed ef eb ca ça. Nesse novo exercício, novos desafios para os alunos, uma vez que estavam postas as vogais precedentes de consoantes, ainda continuando o uso do ç.

Aprendida a referida ordem de letras, o aluno estaria apto a adentrar aos exercícios concretos de observação, de leitura e de escrita de palavras que se formassem a partir daqueles vocábulos. Os que estão contidos na tabela acima, envolvendo monossílabas e trissílabas, permitiriam ao aluno a continuidade de exercícios anteriores, por via de construções de novas palavras.

Lamentavelmente, as lições cinco e seis não foram localizadas nas edições do referido vespertino cearense. Nenhuma referência há nas edições seguintes acerca da suspensão da publicação das referidas aulas.

\section{À guisa de uma Conclusão}

À guisa de uma conclusão, tendo em vista apenas ter se iniciado o debate, acerca de relatos de ações pedagógicas exitosas que visaram à alfabetização de crianças em nosso país, por via do jornal como veículo educativo, pode-se destacar que o trabalho da normalista Ana Facó foi pioneiro na educação a distância no Ceará.

Difícil precisar o alcance social das aulas de primeiras letras. A não localização de fontes impede avaliar a extensão daquela ação pedagógica.

Numa Fortaleza do início do século XX com aproximadamente 50 mil habitantes, demarcados por limites sociais intransponíveis entre os habitantes do centro da cidade e as "areias", assim chamado o subúrbio, habitado pelas pessoas humildes e desprovidas de assistência pública, indaga-se, no plano político, a representação que faziam da educação escolar para os pobres. No centro da cidade, reduto residencial das famílias abastadas, dos negociantes, dos intelectuais, dos militares, das classes médias, não se dava por falta de escolas. Havia escolas públicas e particulares que atendiam a demanda. Nas areias, espaço de ocupação desordenado por pessoas humildes, pobres varridos do meio rural, devido ao ciclo de estiagem no sertão, a infância corria solta, sem escolas. (TEÓFILO, 2001).

Merece ser refletida a experiência pedagógica empreendida pela referida educadora cearense ao pretender alfabetizar crianças pobres, por meio de aulas do ABC, publicadas num jornal local, numa sociedade contraditória com marcas profundas de pouco letramento entre as camadas mais pobres.

No entanto, há de se admitir que, embora tal iniciativa viesse a demonstrar graus de conectividade de mulheres brasileiras, educadoras e beletristas na Primeira República, com o debate internacional que prenunciava a finalidade social da educação, o enfrentamento do problema da universalização da educação escolar pública estava adiado para a posteridade. 


\section{Referências}

ANDRADE, F. A. de. Luzes e sombras na educação. O aciolismo e a criação da Faculdade de Direito do Ceará, 1903-1912. Fortaleza: Inesp, 2008.

AZEVEDO, O. de. Fortaleza Descalça: reminiscências. $2^{\mathrm{a}}$ Ed. Fortaleza: UFC/Casa de J. de Alencar, 1992.

BRASIL. Decreto N ${ }^{\circ} 7.247$ de 19 de abril de 1879. In: BARBOSA, Rui. Reforma do Ensino Secundário e Superior. Obras Completas. v. IX, tomo I, Rio de Janeiro, Ministério da Educação e Saúde, 1942, p. 273-303.

CÂMARA, J. Almanache administrativo, estatístico, mercantil, industrial e literário do Estado Ceará. Anno 13. Fortaleza: Typo-litographia a vapor, 1907.

FACÓ, Ana. O ensino intuitivo: $\mathrm{O}$ - ABC em seis lições para a infância pobre. Jornal do Ceará. Fortaleza-CE, 16 de mar. 1904. Coluna Escola: Primeira e segunda lição p. 3.

. O ensino intuitivo: $\mathrm{O}-\mathrm{ABC}$ em seis lições para a infância pobre. Jornal do Ceará. Fortaleza-CE, 30 de mar. 1904. Coluna Escola: terceira lição, p. 3. $\mathrm{O}$ ensino intuitivo: $\mathrm{O}-\mathrm{ABC}$ em seis lições para a infância pobre. Jornal do Ceará. Fortaleza-CE, 16 de abr. 1904. Coluna Escola: quarta lição, p. 3.

MARCÍLIO, M. L. História da escola pública em São Paulo e no Brasil. São Paulo: Imp. Oficial do Estado de São Paulo; Inst. Fernand Braudel, 2005.

MOACYR, P. A instrução e o Império. Subsídios para a História da Educação no Brasil. $2^{a}$ ed. São Paulo: Cia. Editora Nacional, 1937.

SAVIANI, D. História das idéias pedagógicas no Brasil. Campinas, SP: Autores Associados, 2008.

SOUSA, R. F. de. História da organização do trabalho escolar e do currículo no século $X X$. Ensino primário e secundário no Brasil. São Paulo: Cortez, 2008.

TARDE, G. A opinião e as massas. São Paulo: Marins Fontes, 1992.

TEÓFILO, R. Libertação do Ceará. Fortaleza: Fund. Waldemar Alcântara, 2001.

VALDEMARIN, V. T. Estudando as lições das coisas. Análise dos fundamentos filosóficos do Método de Ensino Intuitivo. Campinas, SP: Associados, 2004.

VEIGA, C. G. História da Educação. São Paulo: Ática, 2007.

VIDAL, D. G; SÁ, E. F. de; SILVA, V. L. G. Obrigatoriedade escolar no Brasil. Cuiabá/ MT: EdUFMT, 2013.

VIEIRA, S. L; FARIAS, I. M. S. de. (Orgs.) Documentos de política educacional no Ceará: Império e República Brasília.- (Coleção Documentos da Educação Brasileira. Regulamento da Instrucção Primaria do Estado do Ceará - 1905 - p. 40). Instituto Nacional de Estudos e Pesquisas Educacionais Anísio Teixeira, 2006. CD-ROM. 
Notas

${ }^{1}$ Este artigo é uma versão atualizada de uma comunicação intitulada Pelo jornal se aprende a ler: "Ensino Intuitivo: o ABC em seis lições" apresentada no XI Encontro Cearense de História da Educação — ECHE I Encontro Nacional do Núcleo de História e Memória da Educação - ENHIME, da Faculdade de Educação Programa de Pós-Graduação em Educação Brasileira - Universidade Federal do Ceará, maio de 2012.

${ }^{2}$ Universidade Federal do Ceará - UFC.

${ }^{3}$ Universidade Federal do Ceará - UFC.

${ }^{4}$ Nasceu no município de Beberibe, sito no litoral leste do Estado do Ceará a $78 \mathrm{~km}$ de Fortaleza. Concluiu as primeiras letras na escola pública da Comarca de Cascavel. Órfã de mãe aos 16 anos de idade veio a residir em Fortaleza, na casa do tio paterno. Conclui o Curso de magistério na Escola Normal do Ceará. Em 1887 começou a lecionar no ensino primário particular. Em 1891 é professora auxiliar nomeada ao estabelecimento de ensino que lhe formara professora. Em 1994 é nomeada Inspetora do Ensino. Foi a primeira mulher cearense diretora do Grupo Escolar Nogueira Accioly, inaugurado em 1907. Além do magistério, foi uma mulher beletrista em seu tempo atuando no jornalismo e na literatura.

${ }^{5}$ Paulino de Almeida Brito nasceu em Manaus. (1858-1919). Jornalista e professor brasileiro. Bacharel pela Faculdade de Direito de Recife. Como intelectual à sua época, atuaria no jornalismo, na política (senador), na literatura e no magistério. Publicaria a Gramática Primária da Língua Portuguesa.

${ }^{6}$ AZEVEDO, Otacílio de. Fortaleza Descalça: reminiscências. ${ }^{\mathrm{a}}$ Ed. Fortaleza: UFC/Casa de J. de Alencar, 1992. O termo aqui usado é uma alegoria. Na época, a maioria das ruas de Fortaleza, principalmente as do subúrbio, fixava-se sobre areia. Como a cidade foi soerguida sobre dunas, prevaleciam nos subúrbios ruas tortuosas com casas de taipas soerguidas sobre areias frouxas, à mercê dos caprichos dos alísios, que sopravam do mar.

${ }^{7}$ BRASIL. Decreto N ${ }^{\circ}$ 7. 247 de 19 de abril de 1879. A referência a respeito se encontra nas recomendações do artigo $4^{\circ}$, noções das coisas. In: BARBOSA, Rui. Reforma do Ensino Secundário e Superior. Obras Completas. v. IX, tomo I, Rio de Janeiro, Ministério da Educação e Saúde, 1942, p. 273-303.

${ }^{8}$ ALMANACH ADMINISTRATIVO, ESTATÍSTICO, MERCANTIL, INDUSTRIAL E LITERÁRIO DO CEARÁ para o ano de 1907. Anno 13º, Fortaleza, Typo -Lithographia a vapor, 1907.

Recebido em junho-13

Aprovado em novembro-13 